\title{
Evaluation of COVID-19 Patients Admitted to Pediatric Emergency Department
}

\begin{tabular}{|c|c|c|}
\hline Author (s) & \multicolumn{2}{|l|}{ (D) Murat Doğan, (1) Binnaz Çelik } \\
\hline $\begin{array}{l}\text { Affiliation } \\
\text { (s) }\end{array}$ & \multicolumn{2}{|c|}{ Kayseri City Hospital, Department of Pediatrics Emergency, Kayseri, Turkey } \\
\hline $\begin{array}{c}\text { Article } \\
\text { Information }\end{array}$ & $\begin{array}{l}\text { Article Type: Original Articles } \\
\text { Article Group: Pediatric Infectious Diseases }\end{array}$ & $\begin{array}{l}\text { Received: } 19.08 .2021 \\
\text { Accepted: } 07.12 .2021 \\
\text { Available Online: } 31.12 .2021\end{array}$ \\
\hline
\end{tabular}

\section{Abstract}

The Coronavirus disease (COVID-19) rapidly spread all around the world and was declared a worldwide pandemic by World Health Organization in March 2020. We aimed to investigate the clinical, demographic and laboratory characteristics of COVID-19 in children admitted to the pediatric emergency triage. Epidemiological, clinical, laboratory, and radiological data of children were collected retrospectively and analyzed to compare by symptoms. A total of 213 pediatric cases with COVID-19 were included. Most of the patients were asymptomatic (63.8\%). The main clinical features were mild symptoms including fever $(7.5 \%)$, cough $(6.5 \%)$, myalgia $(6.3 \%)$ or no $(63.8 \%)$. Of the patients who had CT scan, $25 \%$ had specific findings of COVID-19. Ground-like opacities were common radiological findings $(25 \%)$. Symptomatic patients had higher lymphopenia rate $(p=0.03)$, higher CRP and procalcitonin $(P C T)$ values $(p=0.04, p=0.04)$, lower age $(p<0.001)$ and lower neutrophil count $(p=0.01)$. The rate of neutropenia and leukopenia were higher in asymptomatic patients $(p=0.15$, $p=0.05$, respectively). The most common cause of transmission in children is family contact. Home isolation was recommended for $89.6 \%$ of the patients, $10.3 \%$ were hospitalized, $2.3 \%$ needed an intensive care unit (ICU). Only one death was reported. We found found that children with COVID-19 are generally mild severe or asymptomatic clinic. Young children were relatively more symptomatic than older children, and those with underlying diseases often needed intensive care unit. The most important laboratory findings difference between symptomatic and asymptomatic patients are lymphopenia, increased CRP and PCT values ( $p=0.04$ for all three parameter).

Keywords: COVID-19, children, pediatric emergency

Correspondence: Murat DOĞAN, Kayseri City Hospital, Department of Pediatrics Emergency,

Kayseri, Turkey

E-mail: doktormurat033@hotmail.com 


\section{Introduction}

In the middle of December 2019, an outbreak of coronavirus disease 2019 (COVID-19) caused by severe acute respiratory syndrome coronavirus-2 (SARSCoV-2) occurred in Wuhan, Hubei Province, China, and from there it spread worldwide. ${ }^{1}$ The number of cases outside China rapidly increased, urging the World Health Organization (WHO) to declare COVID-19 as a pandemic on March 11, 2020. ${ }^{2}$ The first case from Turkey was reported on March 13, 2020. As of 24 June 2020, a total of almost 9 million COVID-19 patients including 477634 deaths $(5.2 \%)$ in 216 countries have been confirmed by the WHO. ${ }^{3}$ COVID-19 can rapidly spread from human-tohuman and is more contagious than other notable members of the coronavirus family, such as Middle Eastern respiratory syndrome (MERS) and SARS. ${ }^{4,5}$ This virus is air borne, and thus transmitted via respiratory droplets and direct contact. Common symptoms reported so far include fever, myalgia and dry cough. ${ }^{6}$

\section{Highlights}

- The coronavirus disease (COVID-19), which caused a pandemic by the World Health Organization in March 2020, affects both children and adults.

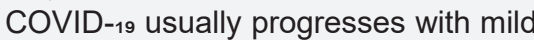
or asymptomatic clinical condition in children compared to adults.

- Home isolation is recommended for the most of patients, but children with underlying diseases (such as prematurity, lung and heart diseases, immunodeficiency, allergic diseases) may need hospitalization.

- There are no significant laboratory findings of COVID-19 $_{-19}$ disease in children, but symptomatic patients may have a higher lymphopenia rate, higher CRP and procalcitonin values, lower age, and lower neutrophil counts.
Children with COVID-19 have been reported to be asymptomatic or with mild clinical symptoms compared to adults. The reason why it is less common in children and has a milder clinical prognosis is unknown. ${ }^{7-9}$ Therefore, knowledge about COVID-19 in children is limited. Although there are many studies on COVID-19 in adults, studies on children are very few compared to adults. In this study, we aimed to evaluate the symptoms and characteristics of children with COVID-19 who were evaluated in the pediatric emergency department.

\section{Material and Method}

A total of 213 children were included in this retrospective study who presented at the Pediatric Emergency Department Triage from March 25 to July 31, 2020. According to the clinic presentation of the patients who admitted to the pediatric emergency triage, the patients were examined in the pediatric pandemic outpatient clinic or the pediatric emergency yellow room. Epidemiological, clinical, laboratory, and radiological data were collected, including the age, sex, clinical signs and symptoms, outcomes, laboratory data, chest X-ray (CXR) findings, chest computed tomography (CT).6,9 All the children were tested with COVID-19 reverse transcriptase-polymerase chain reaction (RT-PCR) tests and were found to be positive. These RT-PCR tests and blood samples were performed in pediatric pandemic outpatient clinics and pediatric emergency yellow areas rooms due to close contact with a confirmed case or with someone presenting with symptoms of COVID-19, such as fever, cough, myalgia, diarrhea, and/or vomiting. Blood tests were complete blood count
Mann-Whitney $U$ test was used for of data that were not normally distributed, and Chi-square test was used for analysis of categorical variables. Values of $p<0.05$ was considered statistically significant.

\section{Results}

In our study 106 (49.8\%) of the patients were male and $107(50.2 \%)$ were female. The mean age of the patients was $9.55 \pm 5.15$ years. The body temperature mean was $37.1 \pm 0.68^{\circ} \mathrm{C}$ and the oxygen saturation mean was $96.2 \pm 2.78 \%$. The median time between the onset of symptoms and diagnosis was $3(0-6)$ days. Vaccines of $96.2 \%$ of the patients were complete, $3.8 \%$ of them were unknown. Most of the patients (99.1\%) had a history of contact with COVID-19 patients, $0.9 \%$ did not know. The contact environment was within the family, social environment and the unknown, respectively. Contact with patients was generally within the family, and they were mothers, fathers, parents, grandparents, and friends, respectively. None of the patients had a history of alcohol or smoking. CXR had that of 95 patients and $12.6 \%$ of these patients had consolidated areas. CT scan had 48 patients and $25 \%$ of them had findings consistent with COVID-19 (ground glass opacities, local patch shadow). Home isolation was recommended for $89.6 \%$ of the patients, $10.3 \%$ were hospitalized, $2.3 \%$ needed an intensive care unit (ICU). Patients who needed an ICU had underlying diseases $(2.3 \%)$ such as obesity, asthma and prematurity. The rate of those who were discharged after recovery was $99.5 \%$, only 1 patient with a history of prematurity died of pneumonia. No treatment was initiated in $71.8 \%$ of 
the patients, only antipyretic was prescribed to $8.5 \%$ of the patients, and antibiotic (Azithromycin: $15 \mathrm{mg} / \mathrm{kg}$ the first day, then $7.5 \mathrm{mg} / \mathrm{kg}$ once a day for other 4 days or Amoxicillin $90 \mathrm{mg} / \mathrm{kg} /$ day in 3 doses, in case of possible oral intake) and antipyretic (10-15 mg/kg every 4-6 h) drugs were prescribed to $15.5 \%$ of the patients (Table 1). There were $136(63.8 \%)$ asymptomatic patients and $77(36.2 \%)$ patients were symptomatic. The symptoms of the patients were fever, cough, myalgia, diarrhea, nausea-vomiting and rash respectively. Important laboratory findings in our study were $5.1 \%$ leukopenia, $8.9 \%$ neutropenia, $16.4 \%$ lymphopenia and $0.5 \%$ thrombocytopenia (Table 2). Symptomatic and asymptomatic patients were compared according to data. There was no significant difference between the groups in terms of gender, leukocyte count, eosinophil count, platelet count and MPV values. Symptomatic patients had lower age, higher fever, lower oxygen saturation, lower neutrophil count and lower lymphocyte count $(p<0.05)$ (Table 3$)$. Leukopenia, neutropenia and thrombocytopenia rates were higher in the asymptomatic group but not statistically significant $(p>0.05)$. In addition, symptomatic patients had significantly higher PCT and CRP values $(p=0.04)$ and higher lymphopenia rate $(p=0.04)$ (Table 3$)$. PCT values of $19.9 \%$ of the patients were above $0.1 \mathrm{ng} / \mathrm{ml}$ and most of them were symptomatic patients $(82.8 \%)$.

\section{Table 1}

Demographic findings and clinical presentation of Covid-19 pediatric patients

\begin{tabular}{|c|c|c|}
\hline Age (year) (mean \pm std) & \multicolumn{2}{|c|}{$9.55 \pm 5.15$} \\
\hline \multicolumn{3}{|l|}{ Gender (n) (\%) } \\
\hline Male & 106 & 49.8 \\
\hline Female & 107 & 50.2 \\
\hline Fever $\left({ }^{\circ} \mathrm{C}\right)$ & \multicolumn{2}{|c|}{$37.1 \pm 0.68$} \\
\hline $\mathrm{SpO}_{2}(\%)$ & \multicolumn{2}{|c|}{$96.2 \pm 2.7$} \\
\hline \multicolumn{3}{|c|}{ Contact environment (n) (\%) } \\
\hline Family & 193 & 90.6 \\
\hline Social & 18 & 8.5 \\
\hline Unknown & 2 & 0.9 \\
\hline \multicolumn{3}{|l|}{ Hospitalization (n) (\%) } \\
\hline No & 191 & 89.7 \\
\hline Service & 17 & 8.0 \\
\hline ICU & 5 & 2.3 \\
\hline \multicolumn{3}{|l|}{$\operatorname{CXR}(n)(\%)$} \\
\hline No & 118 & 55.4 \\
\hline Normal & 83 & 38.9 \\
\hline Consolidation & 12 & 5.7 \\
\hline \multicolumn{3}{|l|}{ CT $(n)(\%)$} \\
\hline No & 165 & 77.5 \\
\hline Normal & 36 & 16.9 \\
\hline COVID specific & 12 & 5.6 \\
\hline Underlying disease & \multicolumn{2}{|c|}{52.3} \\
\hline \multicolumn{3}{|l|}{ Treatment (n) (\%) } \\
\hline No & 153 & 71.8 \\
\hline NSAI & 18 & 8.5 \\
\hline $\mathrm{Ab}$ and NSAI & 33 & 15.5 \\
\hline Ab, NSAİ, plaquenil & 9 & 4.2 \\
\hline \multicolumn{3}{|l|}{ Discharge } \\
\hline Yes & 212 & 99.5 \\
\hline Death & 1 & 0.5 \\
\hline
\end{tabular}

Abbreviations: $\mathrm{Ab}$, antibiotic; $\mathrm{CXR}$, Chest X-ray; $\mathrm{CT}$, computed tomography; ICU, intensive care unit; NSAI, non steroidal anti inflammatory; $\mathrm{SpO}_{2}$, oxygen saturation.
Table 2

Clinical and laboratory findings of Covid-19 pediatric patients

\begin{tabular}{|c|c|c|}
\hline WBC $(\mu \mathrm{L})($ mean \pm std $)$ & \multicolumn{2}{|c|}{$6949 \pm 2802$} \\
\hline PLT (109 /L) (mean \pm std) & \multicolumn{2}{|c|}{$278 \pm 124$} \\
\hline MPV (fL) (mean \pm std) & \multicolumn{2}{|c|}{$9.6 \pm 0.9$} \\
\hline CRP (mg/L) (mean $\pm s t d)$ & \multicolumn{2}{|c|}{$5.6 \pm 12.4$} \\
\hline \multicolumn{3}{|l|}{ PCT $(n g / m L)$} \\
\hline$<0.1$ & \multicolumn{2}{|c|}{$143(67.1)$} \\
\hline$>0.1$ & \multicolumn{2}{|c|}{$70(32.9)$} \\
\hline Neutrophil $(\mu \mathrm{L})($ mean \pm std) & \multicolumn{2}{|c|}{$3218 \pm 1912$} \\
\hline Lymphocyte $(\mu \mathrm{L})$ (mean \pm std) & \multicolumn{2}{|c|}{$3157 \pm 2706$} \\
\hline Leukopenia (n) (\%) & 11 & 5.1 \\
\hline Neutropenia (n) (\%) & 19 & 8.9 \\
\hline Lymphopenia (n) (\%) & 35 & 16.4 \\
\hline Thrombocytopenia (n) (\%) & 1 & 0.5 \\
\hline \multicolumn{3}{|l|}{ Symptom (n) (\%) } \\
\hline Fever & 16 & 7.5 \\
\hline Cough & 14 & 6.5 \\
\hline Fever and cough & 6 & 2.8 \\
\hline Myalgia & 13 & 6.3 \\
\hline Nausea-vomiting & 9 & 4.2 \\
\hline Diarrhea & 11 & 5.2 \\
\hline Rash & 3 & 1.4 \\
\hline Conjunctivitis & 2 & 0.9 \\
\hline Loss of taste and smell & 3 & 1.4 \\
\hline \multicolumn{3}{|l|}{ Clinic types $(\%)$} \\
\hline Asymptomatic & \multicolumn{2}{|c|}{63.8} \\
\hline Mild & \multicolumn{2}{|c|}{27.9} \\
\hline Moderate & \multicolumn{2}{|c|}{6.0} \\
\hline Severe & \multicolumn{2}{|c|}{2.3} \\
\hline
\end{tabular}

Abbreviations: WBC, white blood cell; PLT, platelet; MPV, mean platelet volüme; CRP, C-reaktif protein; PCT, procalcitonin.

\section{Table 3}

The comparison of demographic, clinic and laboratory data between symptomatic and asymptomatic patients

\begin{tabular}{lccc}
\hline & $\begin{array}{c}\text { Symptomatic } \\
\text { Patients } \\
\text { Median (min-max) }\end{array}$ & $\begin{array}{c}\text { Asymptomatic } \\
\text { Patients } \\
\text { Median(min-max) }\end{array}$ & p \\
\hline Age (year) & $8(1-17)$ & $12(2-17)$ & $<0.001$ \\
Gender $($ male) $(\mathrm{n})$ & 67 & 39 & 0.84 \\
Fever $\left({ }^{\circ} \mathrm{C}\right)$ & $37.4(36-39.1)$ & $37(36-37.9)$ & $<0.001$ \\
$\mathrm{SpO}_{2}(\%)$ & $96(88-99)$ & $97(90-99)$ & $<0.001$ \\
$\mathrm{WBC}(\mu \mathrm{L})$ & $6355(2680-18000)$ & $6140(3950-20450)$ & 0.77 \\
Neutrophil $(\mu \mathrm{L})$ & $2720(690-14270)$ & $3230(650-16390)$ & 0.01 \\
Lymphocyte $(\mu \mathrm{L})$ & $2475(630-31550)$ & $2670(310-7860)$ & 0.03 \\
PLT $(109 / \mathrm{L})$ & $267(32-546)$ & $255(159-510)$ & 0.16 \\
$\mathrm{MPV}(\mathrm{fL})$ & $9.4(8-13.6)$ & $9.5(8-12)$ & 0.36 \\
$\mathrm{CRP}(\mathrm{mg} / \mathrm{L})$ & $1.8(0-116)$ & $1.3(0-73)$ & 0.04 \\
\hline
\end{tabular}

Abbreviations: WBC, white blood cell; PLT, platelet; MPV, mean platelet volüme; CRP, C-reaktif protein; $\mathrm{SpO}_{2}$, oxygen saturation.

\section{Discussion}

Coronavirus disease 2019, which causes pandemics all over the world, affects both children and adults. It presents a milder or asymptomatic clinical prognosis in children compared to adults. Children of all ages can be infected, including newborn infants and young children. ${ }^{10}$ In the largest Chinese paediatric case series to date, of 2143 subjects, the median age at paediatric diagnosis was $7(2-13)$ years and 1213 cases $(56.6 \%)$ were boys. ${ }^{11}$ In another study with 820 pediatric COVID-19 cases, it was reported that the mean age of the patients was 
7 years 3 months (range of 1 day to 17 years) and $466(56.8 \%)$ cases were male. ${ }^{12}$ The mean age of our patients $9.55 \pm 5.15$ years and $49.8 \%$ were male. There was no significant sex difference in our cases, but the symptomatic group was significantly younger. Still, there is no direct evidence supporting whether male or female are more susceptible to SARS-CoV-2 infection. Children with positive COVID-19 PCR tests mostly have a history of social and/or familial environmental contact. This condition can be accepted as a definite indicator of high human-to-human transmission and contagiousness. Intra-family transmission is very important. ${ }^{7,13} 94.8 \%$ of our patients had contact with patients who were positive COVID-19 PCR test within the family, and these were mothers, fathers, parents, grandparents and friends, respectively. The median time from onset of illness to diagnosis was 2 day (range: $0-42$ day). ${ }^{11}$ In our study, the median time from onset of the disease to diagnosis was $3(0-6)$ days.

According to clinical characteristics of existing pediatric cases, children with COVID-19 can be divided into five clinical types: asymptomatic infection, mild, moderate, severe, and critically severe. ${ }^{14,15}$ Multiple reports have demonstrated that children and young adults have a milder form of the disease compared to adults. Asymtomatic, mild and moderate infections comprise over $90 \%$ of all children who have tested positive for COVID-19. ${ }^{16-18}$ In the review of the studies regarding COVID-19 in children published before March 2020, most children with COVID-19 had mild symptoms, showing a good prognosis, and recovered within 1 to 2 weeks. ${ }^{19}$ A minority of children with COVID-19 require hospitalization. By March, among 2572 cases of COVID-19 in children reported from the US, the estimated rate of hospitalization differed from $6 \%$ to $20 \%$, and $0.58 \%-2.0 \%$ of them were admitted to an ICU. ${ }^{18}$ Of 171 children treated at Wuhan Children's Hospital, three $(1.8 \%)$ required intensive care and all of those had underlying diseases. ${ }^{11}$ In our study, $63.8 \%$ of our patients were asymptomatic and rate of hospitalization $10.3 \%$. Five patients required ICU, all of those had underlying diseases such as prematurity, asthma, obesity, and Down syndrome. There was only one death of a 2-month -old child with prematurity and pneumonia. Although the certain cause is unknown, children with COVID-19 appear to have a milder clinical course compared to adults, and reports of death are scarce. The prognosis seems to be very good, with recovery described in the vast majority of reported cases. ${ }^{20}$ In our study, $99.5 \%$ of the patients had a good prognosis and they recovered. The possible reasons for lower number and milder infections in children and young adults include lower exposure to virions, being isolated at home and minimal exposure to pollution and cigarette smoke contributing to healthier respiratory tracts. Additionally, the distribution, maturation and functioning of viral receptors such as angiotensin converting enzyme 2 (ACE2) may be important in age-dependent susceptibility to severe COVID-19. ${ }^{11,21}$

The most common symptoms described at onset in children are fever and cough. Other clinical features include sore throat, fatigue, myalgia, nasal congestion, runny nose, sneezing, headache, dizziness, vomiting, and abdominal pain. Some children and newborns exhibit atypical symptoms, manifested as vomiting, diarrhea, and other gastrointestinal symptoms, or only asthma and shortness of breath. ${ }^{22-24}$ In a study of 2143 children, the patients' symptoms were typical of acute respiratory infections and included cough, fever, myalgia, sore throat, sneezing and fatigue..$^{11}$ In a series of 291 pediatric cases from the (US), the most common symptoms were fever, cough, and shortness of breath, respectively. ${ }^{18}$ Similar to the literature, the most common symptoms in our patients were fever, cough, myalgia and gastroenteritis, respectively.

The most common investigations used for imaging COVID-19 patients are CXR and CT. CXR is usually the first-line investigation due to ease of availability. CXR findings in children appear to be non-specific. Children with mild disease should not routinely need computed tomography (CT) chest imaging in view of the high radiation exposure. ${ }^{24-26}$ The main radiological features in pediatric patients with COVID-19 have been reported to be ground-glass opacities, consolidations with surrounding halo signs, patchy shadows are considered typical of pediatric patients. ${ }^{18,20,25}$ Yasuhara et al. ${ }^{27}$ founded that $54 \%$ of the pediatric patients had ground-glass opacities, and most of them had mild symptoms or were without any symptoms. Lu et al. ${ }^{20}$ reported that ground-glass opacity was seen in a third of 171 diagnosed children. Local or bilateral patchy shadowing was seen in $18.7 \%$ and $12.3 \%$, respectively. Overall, $15.8 \%$ of children did not have symptoms of infections or radiological features of pneumonia. ${ }^{20} 7.3 \%$ of our patients who underwent CXR had consolidated areas, and all of these patients were symptomatic. In the CT scan of the patients in our study $(25 \%)$, there were findings consistent with COVID-19 (groundglass opacities, local patch shadow). COVID-19 has mostly been diagnosed using nasal or pharyngeal swabs or blood specimens that were positive for 2019-nCoV nucleic acid using real-time, reverse transcriptase-polymerase chain reaction assays (RTPCR). Alternative diagnostics have included genetic sequencing of specimens from the respiratory tract or blood consistent with SARS-CoV2. CXR and CT scan pictures in moderate to severe illness are suggestive of diffuse bilateral involvement of lungs. ${ }^{28}$ Diagnosis of all patients was confirmed by RT-PCR test of nasal and oropharyngeal specimens.

Typical abnormal laboratory findings were reported such as lymphopenia (31\%), leucopenia (19\%), and elevated creatine kinase- MB $(31 \%)$ and procalcitonin $(17 \%)$ levels in the cohort of pediatric patients with COVID-19.8 Xia W et al. ${ }^{25}$ showed the laboratory findings in pediatric patients with COVID-19, including lymphopenia (35\%) and elevated ALT (25\%), creatine kinase-MA (75\%), CRP (45\%), and procalcitonin $(80 \%)$ levels. Yasuhara et al. ${ }^{27}$ found similar laboratory findings such as lymphopenia and elevated CRP, ALT, and AST levels in children with COVID-19. The significance of blood inflammatory markers remains controversial, particularly in children. In a study found that over two-third $(68.7 \%, n=57)$ of cases had a normal 
WBC and a normal CRP in $70.1 \%(n=47 / 67)$ of cases. ${ }^{12}$ Henry et al. ${ }^{29}$ summarized the findings from 12 studies on 66 children and reported normal leucocyte counts $(69.2 \%)$, neutropenia $(6.0 \%)$, neutrophilia $(4.6 \%)$ and lymphopenia $(3.0 \%)$. CRP and PCT were high only in $13.6 \%$ and $10.6 \%$ of cases, respectively. Similar to the literature, we found $5.1 \%$ leukopenia, $8.9 \%$ neutropenia, $16.4 \%$ lymphopenia, $0.5 \%$ thrombocytopenia, $18.7 \%$ elevated CRP and $17.9 \%$ elevated PCT in our study. Symptomatic patients had higher lymphopenia rate, CRP and PCT values. The rate of neutropenia and leukopenia were higher in asymptomatic patients than in symptomatic patients. There was no significant difference between the symptomatic and asymptomatic groups in terms of leukocyte count, eosinophil count, platelet count, and mean platelet volume.

Current WHO recommendation for all patients with mild symptoms include antipyretics and self-isolation at the patient's home. The general strategies include resting and supportive treatments, sufficient calorie, and water intake, maintaining waterelectrolyte balance, and homeostasis. ${ }^{18,30}$ Patients and household members should be educated about personal hygiene, infection control measures to prevent the infection from spreading to household contacts. Paracetamol (10-15 mg/ $\mathrm{kg}$ every $4-6 \mathrm{~h}$ ) can prefer in case of fever $>38.5^{\circ} \mathrm{C}$. Avoid ibuprofen in case of dehydration, vomiting and diarrhea, as it is associated with an increased risk of kidney failure. ${ }^{31}$ There is no need for antibiotic treatment routinely. If there is clinical or laboratory evidence of secondary bacterial infection, appropriate antibiotics should be used appropriately. ${ }^{18}$

Management of Hospitalized Cases: Oxygen supplementation to maintain $\mathrm{SpO}_{2}>92 \%$. Symptomatic treatment: Paracetamol for fever, Blood culture sample should be sent at time of admission before starting anti-microbials. Empirical antimicrobials (e.g., Ceftriaxone) within $1 \mathrm{~h}$ of admission in case of suspected sepsis and septic shock. Oseltamivir may be considered after sending appropriate investigation if influenza is suspected. Systemic corticosteroids are not recommended, unless indicated for any other reason. ${ }^{32}$ No specific antivirals have been proven to be effective as per currently available data. Hydroxychloroquine and chloroquine have been demonstrated to have antiSARSCoV-2 activity in in-vitro studies. Mechanisms for anti-viral activity of hydroxychloroquine include inhibiting membrane fusion by increasing $\mathrm{pH}$ of endosome/lysosome, inhibiting virus entry by changing glycosylation of ACE2 receptor and spike protein, and immune-modulation. ${ }^{33,34}$ Similar to the literature, we did not prescribe any treatment to $71.8 \%$ of our patients but $8.5 \%$ only oral paracetamol, $15.5 \%$ antibiotic and paracetamol, $4.2 \%$ antibiotic, paracetamol and hydroxychloroquine treatment. Appropriate antibiotics were used appropriately for patients with clinical or laboratory evidence of secondary bacterial infection. There were several limitations to our study. Our study was single centered. All patients in our study did not have liver and kidney function tests, and coagulation panel.

\section{Conclusion}

According to our study COVID-19 is asymptomatic or mildly severe in children. Lymphopenia, CRP and PCT elevation, ground-glass opacities on chest CT were important findings of COVID-19 disease. Most of the children recover without hospitalization and without any treatment. In those with underlying diseases (obesity, asthma, prematurity history, etc.) COVID-19 can be severe and need ICU.

Author Contributions: All of the authors declare that they have all participated in the design, execution, and analysis of the paper, and that they have approved the final version.

Conflict of Interest: There are no conflicts of interest in connection with this paper, and the material described is not under publication or consideration for publication elsewhere.

Ethics Committee Approval: Ethical approval was obtained from the local ethics committee (135/06.08.2020).

Financial Disclosure: The authors declared that this study has received no financial support.

Informed Consent: Because the study was designed retrospectively, no written informed consent form was obtained from patients.

\section{References}

1. Li Q, Guan X, Wu P, et al. Early Transmission Dynamics in Wuhan, China, of Novel Coronavirus-Infected Pneumonia. N Engl J Med. 2020;382(13):1199-1207. [CrossRef]

2. World Health Organization. WHO Director-General's opening remarks at the media briefing on COVID-19 - 11 March 2020. [CrossRef] Accessed 16 Jun 2020.

3. Chan JF, Yuan S, Kok KH, et al. A familial cluster of pneumonia associated with the 2019 novel coronavirus indicating personto-person transmission: a study of a family cluster. Lancet. 2020;395(10223):514-523. [CrossRef]

4. Cao Q, Chen YC, Chen CL, Chiu CH. SARS-CoV-2 infection in children: Transmission dynamics and clinical characteristics. J Formos Med Assoc. 2020;119(3):670-673. [CrossRef] 10.1016/j. jfma.2020.02.009

5. Lee $\mathrm{PI}, \mathrm{Hu} \mathrm{YL}$, Chen $\mathrm{PY}$, Huang YC, Hsueh PR. Are children less susceptible to COVID-19?. J Microbiol Immunol Infect. 2020;53(3):371-372. [CrossRef]

6. Chen N, Zhou M, Dong X, et al. Epidemiological and clinical characteristics of 99 cases of 2019 novel coronavirus pneumonia in Wuhan, China: a descriptive study. Lancet. 2020;395(10223):507513. [CrossRef]

7. Dong $\mathrm{Y}, \mathrm{Mo} \mathrm{X}, \mathrm{Hu} \mathrm{Y}$, et al. Epidemiology of COVID-19 Among Children in China. Pediatrics. 2020;145(6):e20200702. [CrossRef]

8. Qiu H, Wu J, Hong L, et al. Clinical and epidemiological features of 36 children with coronavirus disease 2019 (COVID-19) in Zhejiang, China: an observational cohort study. Lancet Infect Dis. 2020;20:689-696. [CrossRef]

9. Tagarro A, Epalza C, Santos M, et al. Screening and severity of coronavirus disease 2019 (COVID-19) in children in Madrid, Spain. JAMA pediatrics. 2020. [CrossRef]

10. Wei M, Yuan J, Liu Y, Fu T, Yu X, Zhang ZJ. Novel Coronavirus Infection in Hospitalized Infants Under 1 Year of Age in China. JAMA. 2020;323(13):1313-1314. [CrossRef]

11. Dong $\mathrm{Y}, \mathrm{Mo} \mathrm{X}, \mathrm{Hu} \mathrm{Y}$, et al. Epidemiology of COVID-19 Among Children in China. Pediatrics. 2020;145(6):e20200702. [CrossRef]

12. Tung Ho CL, Oligbu $P$, Ojubolamo $O$, et al. Clinical Characteristics of Children with COVID-19. AIMS Public Health. 2020 May 6;7(2):258-273. [CrossRef] 
13. Jiehao C, Jin X, Daojiong L, et al. A Case Series of Children With 2019 Novel Coronavirus Infection: Clinical and Epidemiological Features. Clin Infect Dis. 2020;71(6):1547-1551. [CrossRef]

14. Yi J, Xiaoxia L, Runming J, et al. Novel coronavirus infections: standard/protocol/guideline recommendations for the diagnosis, prevention and control of the 2019 novel coronavirus infection in children (the second edition). Chin J Appl Clin Pediatr. 2020;35(2):143-150. [CrossRef]

15. World Health Organization. Clinical management of severe acute respiratory infection when novel coronavirus (nCoV) infection is suspected: Interim Guidance 13 March 2020. [CrossRef] Accessed 26 Jun 2020.

16. Han Q, Lin Q, Jin S, You L. Coronavirus 2019-nCoV: A brief perspective from the front line. J Infect. 2020;80(4):373-377. [CrossRef]

17. Sun P, Lu X, Xu C, Sun W, Pan B. Understanding of COVID-19 based on current evidence. J Med Virol. 2020;92(6):548-551. [CrossRef]

18. Chen ZM, Fu JF, Shu Q, et al. Diagnosis and treatment recommendations for pediatric respiratory infection caused by the 2019 novel coronavirus. World J Pediatr. 2020;16(3):240-246. [CrossRef]

19. Castagnoli R, Votto M, Licari A, et al. Severe Acute Respiratory Syndrome Coronavirus 2 (SARS-CoV-2) Infection in Children and Adolescents: A Systematic Review. JAMA Pediatr. 2020;174(9):882-889. [CrossRef]

20. Lu X, Zhang L, Du H, et al. SARS-CoV-2 infection in children. $\mathrm{N}$ Engl J Med. 2020;382:1663-1665. [CrossRef]

21. Murray MA, Chotirmall SH. The impact of immunosenescence on pulmonary disease. Hindawi [Internet]. 2015 Jun 24. Available from: [CrossRef] Accessed on April 06, 2020

22. Lifen $Y$, Zhenyuan $D$, Mengqi $D$, et al. Suggestions for medical staff from department of pediatrics during the treatment of 2019nCoV infection/pneumonia. J N Med (PrePrint). 2020. [CrossRef]

23. Hu T, Fang L, Junling W, et al. Clinical characteristics of 2019 novel coronavirus (2019-nCoV) infection in children and family prevention and control. Med J Wuhan Univ (PrePrint). 2020. [CrossRef]
24. Çetin BŞ. SARS-CoV-2 Infection in Children; What Do We Know So Far? J Pediatr Acad 2020; 1: 76-85. [CrossRef] 10.38092/jpa2020-849794

25. Xia W, Shao J, Guo Y, Peng X, Li Z, Hu D. Clinical and CT features in pediatric patients with COVID-19 infection: Different points from adults. Pediatr Pulmonol. 2020;55(5):1169-1174. [CrossRef]

26. Li W, Cui H, Li K, Fang Y, Li S. Chest computed tomography in children with COVID-19 respiratory infection. Pediatr Radiol. 2020 May;50(6):796-799. [CrossRef]

27. Ai T, Yang Z, Hou H, et al. Correlation of chest CT and RT-PCR testing in coronavirus disease 2019 (COVID-19) in China: a report of 1014 cases. Radiology. 2020;296(2):E32-E40. [CrossRef]

28. Yasuhara J, Kuno T, Takagi H, Sumitomo N. Clinical characteristics of COVID-19 in children: A systematic review. Pediatr Pulmonol. 2020 Oct;55(10):2565-2575. [CrossRef]

29. Henry BM, Lippi G, Plebani M. Laboratory abnormalities in children with novel coronavirus disease 2019. Clin Chem Lab Med. 2020;58(7):1135-1138. [CrossRef] 10.1515/cclm-2020-0272

30. Jiehao C, Jin X, Daojiong L, et al. A Case Series of children with 2019 novel coronavirus infection: clinical and epidemiological features. Clin Infect Dis. 2020 Sep 12;71(6):1547-1551. [CrossRef]

31. Day M. Covid-19: ibuprofen should not be used for managing symptoms, say doctors and scientists. BMJ. 2020;368:m1086. [CrossRef]

32. Simonds AK, Hanak A, Chatwin M, et al. Evaluation of droplet dispersion during non-invasive ventilation, oxygen therapy, nebuliser treatment and chest physiotherapy in clinical practice: implications for management of pandemic influenza and other airborne infections. Health Technol Assess. 2010;14(46):131-172. [CrossRef]

33. Liu J, Cao R, Xu M, et al. Hydroxychloroquine, a less toxic derivative of chloroquine, is effective in inhibiting SARS-CoV-2 infection in vitro. Cell Discov. 2020;6:16. Published 2020 Mar 18. [CrossRef]

34. Özdemir Çiçek S, Paç Kısaarslan A. Pediatric Rheumatologists' Perspective on Corona Virus Disease 2019. J Pediatr Acad 2020; 1(1): 3-7. [CrossRef] 